\title{
An Environmentally-friendly Precursor, Ferrous Acetate, in preparation for Monodisperse Iron Oxide Nanoparticles
}

\author{
Yong Jae Suh ${ }^{1 *}$, Dae Sup Kil ${ }^{1}$, Kang Sup Chung ${ }^{1}$, Hyo Sook Lee ${ }^{1}$, and Huiping Shao ${ }^{2}$ \\ ${ }^{1}$ Nano-Materials Group, Korea Institute of Geoscience \& Mineral Resources, Daejeon 305-350, Korea \\ ${ }^{2}$ School of Materials Science and Engineering, University of Science and Technology Beijing, Beijing 100083, China
}

(Received 14 August 2008, Received in final form 9 September 2008, Accepted 10 September 2008)

\begin{abstract}
Almost monodisperse iron oxide nanoparticles with an average particle size ranging from 5 to 43 nm were fabricated using an environmentally friendly starting material, ferrous acetate. The smallest particles were formed in the presence of a reductant, 1,2-dodecanediol, while the particle size increased with increasing concentration of dispersing agents. The dispersants consisted of various combinations of oleic acid, oleylamine, trioctylphosphine, and polyvinylpyrrolidone. The threshold temperature to form crystalline particles was found to be 240 ${ }^{\circ} \mathrm{C}$. The $43 \mathrm{~nm}$ nanoparticles exhibited a room temperature saturation magnetization and coercivity of $57 \mathrm{emu} /$ g and 47 Oe, respectively.
\end{abstract}

Keywords : magnetic materials, nanomaterials, toxicity, starting material, iron(II) acetate, thermal decomposition

\section{Introduction}

Magnetite nanoparticles have been studied extensively on account of their excellent magnetic properties and chemical stability, and have found important applications in magnetic recording, ferrofluids, magnetic resonance imaging, and magnetically guided drug delivery. These magnetic nanoparticles were prepared by a variety of methods, such as co-precipitation [1, 2], spray drying [3], microemulsion process $[4,5]$, and sonochemistry [6-8]. Among the many iron reactants used as iron precursors, iron pentacarbonyl $\left[\mathrm{Fe}(\mathrm{CO})_{5}\right]$ is used most often [9-11] despite its strong toxicity. The other precursors widely used are ferric chloride $\left(\mathrm{FeCl}_{3}\right)$ and ferrous chloride $\left(\mathrm{FeCl}_{2}\right)[1,2,8]$, which are also toxic or harmful. On the other hand, ferrous acetate is a non-toxic precursor that is rarely used in the synthesis of iron oxide nanoparticles [12]. This study examined whether ferrous acetate could be used to synthesize monodisperse magnetite nanoparticles with a controllable size and crystallinity. Vijayakumar et al. synthesized $10 \mathrm{~nm}$ magnetite nanoparticles by the sonochemical oxidation of an aqueous ferrous acetate solution [12]. However, there are no reports of the sizecontrolled production of magnetite nanoparticles from

*Corresponding author: Tel: $+82-42-868-3570$

Fax: +82-42-868-3418, e-mail: aumsuh@kigam.re.kr ferrous acetate. In this study, monodisperse magnetite nanoparticles were synthesized by thermal decomposition using iron(II) acetate as a precursor. The particle size and crystallinity were controlled by varying the reaction temperature and dispersing agents.

\section{Experimental}

The nanoparticles were prepared by heating a reaction solution of the precursor in the presence of stabilizing agents. A precursor iron(II) acetate $(0.348 \mathrm{~g}, 0.002 \mathrm{~mol}$; 99.995\%, Aldrich) and a reducing agent 1,2-dodecanediol $(1.21 \mathrm{~g}, 0.006 \mathrm{~mol} ; 90 \%$, Aldrich) were dissolved in 30 $\mathrm{ml}$ of trioctylamine (TOA, bp $365-367^{\circ} \mathrm{C}$, Junsei Chemical Co.). The solution was then mixed with various combinations of oleic acid (bp 194-195 ${ }^{\circ} \mathrm{C}$, Aldrich), oleylamine (bp $196-199^{\circ} \mathrm{C}$, Aldrich), trioctylphosphine (TOP, bp 284$291{ }^{\circ} \mathrm{C}$, Aldrich) and polyvinylpyrrolidone (PVP, bp $>300^{\circ} \mathrm{C}$, Aldrich). Table 1 lists the mixture constituents along with the properties of the resulting iron oxide nanoparticles. The mixed solution was placed in a $250 \mathrm{ml}$ three-neck distillation flask and heated to $240^{\circ} \mathrm{C}$ for 60 $\mathrm{min}$ in a high-purity nitrogen gas environment to produce magnetite nanoparticles. The particles were then dried before being analyzed by transmission electron microscopy (TEM), X-ray diffraction (XRD), and vibrating sample magnetometry (VSM). 
Table 1. Properties of the iron oxide nanoparticles prepared with various reaction agents.

\begin{tabular}{|c|c|c|c|c|c|c|c|c|}
\hline \multirow{2}{*}{$\begin{array}{l}\text { Run } \\
\text { No. }\end{array}$} & \multirow{2}{*}{$\begin{array}{l}\mathrm{T}_{\mathrm{R}}{ }^{\mathrm{a}} \\
\left({ }^{\circ} \mathrm{C}\right)\end{array}$} & \multicolumn{3}{|c|}{ Reactants used } & \multicolumn{4}{|c|}{ Properties of nanoparticles } \\
\hline & & Reductant & Surfactants & $\begin{array}{l}\text { Dispersing } \\
\text { agents }\end{array}$ & $\begin{array}{l}\text { Size } \\
(\mathrm{nm})\end{array}$ & $\begin{array}{l}\sigma^{f} \\
(\%)\end{array}$ & $\begin{array}{c}\mathrm{M}_{\mathrm{S}}{ }^{\mathrm{g}} \\
(\mathrm{emu} / \mathrm{g})\end{array}$ & $\begin{array}{l}\mathrm{H}_{\mathrm{C}}{ }^{\mathrm{h}} \\
(\mathrm{Oe})\end{array}$ \\
\hline $\mathrm{R} 1$ & 230 & None & $\begin{array}{l}\mathrm{OA}^{\mathrm{b}} 0.8 \mathrm{ml} \\
\mathrm{OY}^{\mathrm{c}} 0.8 \mathrm{ml}\end{array}$ & $\begin{array}{l}\text { TOP }^{\mathrm{d}} 0.2 \mathrm{ml} \\
\text { PVP }^{\mathrm{e}} 0.03 \mathrm{~g}\end{array}$ & 26 & 10 & 38 & 48 \\
\hline $\mathrm{R} 2$ & 230 & Added & $\begin{array}{l}\text { OA } 0.8 \mathrm{ml} \\
\text { OY } 0.8 \mathrm{ml}\end{array}$ & $\begin{array}{l}\text { TOP } 0.2 \mathrm{ml} \\
\text { PVP } 0.03 \mathrm{~g}\end{array}$ & 5 & 13 & 32 & 7 \\
\hline R3 & 240 & None & $\begin{array}{l}\text { OA } 0.8 \mathrm{ml} \\
\text { OY } 0.8 \mathrm{ml}\end{array}$ & $\begin{array}{l}\text { TOP } 0.2 \mathrm{ml} \\
\text { PVP } 0.03 \mathrm{~g}\end{array}$ & 43 & 8 & 57 & 47 \\
\hline $\mathrm{R} 4$ & 240 & Added & $\begin{array}{l}\text { OA } 1.0 \mathrm{ml} \\
\text { OY } 1.0 \mathrm{ml}\end{array}$ & $\begin{array}{l}\text { TOP } 0.3 \mathrm{ml} \\
\text { PVP } 0.03 \mathrm{~g}\end{array}$ & 6 & 11 & 37 & 7 \\
\hline R5 & 240 & Added & $\begin{array}{l}\text { OA } 1.0 \mathrm{ml} \\
\text { OY } 1.5 \mathrm{ml}\end{array}$ & $\begin{array}{l}\text { TOP } 0.6 \mathrm{ml} \\
\text { PVP } 0.03 \mathrm{~g}\end{array}$ & 13 & 13 & 55 & 25 \\
\hline
\end{tabular}

$\overline{{ }^{a} \mathrm{~T}_{\mathrm{R}} \text { : reaction temperature; }{ }^{\mathrm{b}} \mathrm{OA} \text { : oleic acid; }{ }^{\mathrm{c} O Y} \text { : oleylamine; }{ }^{\mathrm{d}} \mathrm{TOP} \text { : trioctylphosphine; }{ }^{\mathrm{e}} \mathrm{PVP} \text { : polyvinylpyrrolidone; }{ }^{\mathrm{f}} \sigma \text { : standard deviation; }{ }^{\mathrm{g}} \mathrm{M}_{\mathrm{S}}: \text { sat- }}$ uration magnetization; ${ }^{\mathrm{h}} \mathrm{H}_{\mathrm{C}}$ : coercivity

\section{Results and Discussion}

The effects of the reductant, 1,2-dodecanediol, on the particle growth at $230^{\circ} \mathrm{C}$ were examined (R1 and R2 in Table 1). Without the reductant, the iron oxide particles had an average size of $26 \mathrm{~nm}$. On the other hand, the average size decreased to $5 \mathrm{~nm}$ in the presence of the reductant [Fig. 1(a) and 1(b)]. The standard deviation, $\sigma$, of their size distribution slightly changed from $10 \%$ to $13 \%$ after adding the reductant, suggesting that their monodispersity had been retained. The addition of the reductant greatly reduced the particle size due to the much faster nucleation rates generating a much larger number of nuclei. Therefore, the addition of the reductant enhanced the formation of the metal monomer, leading to a higher supersaturation. As a result, the particles could not grow larger in the presence of the reductant.

Although the shape of the nanoparticles prepared at 230
${ }^{\circ} \mathrm{C}$ was quite clear, as shown in Fig. 1(a), the crystallinity was very poor [Fig. (2)]. The reaction temperature was increased to $240^{\circ} \mathrm{C}$ with the other conditions fixed (R3 in Table 1) to obtain a more crystalline phase [Fig. (2)]. The nanoparticles had a very narrow size distribution $(\sigma=$ $8 \%$ ) but the average size increased to $43 \mathrm{~nm}$ [Fig. 1(c)]. As the reaction temperature increased, the reactivity of the precursor increased to favor higher crystallinity and larger particles. It should be noted in the enlarged picture in Fig. 1(c) that each particle consisted of several smaller units that were not fully evolved into a homogeneousphase single particle. The size of the discrete parts of the particle was approximately $27 \mathrm{~nm}$ in diameter, which is much the same as that of Run R1.

The saturation magnetization of the nanoparticles decreased from $57 \mathrm{emu} / \mathrm{g}$ to $38 \mathrm{emu} / \mathrm{g}$ with decreasing particle size (Table 1), due presumably to the coated outer layer and higher surface-to-volume ratio [13]. At this
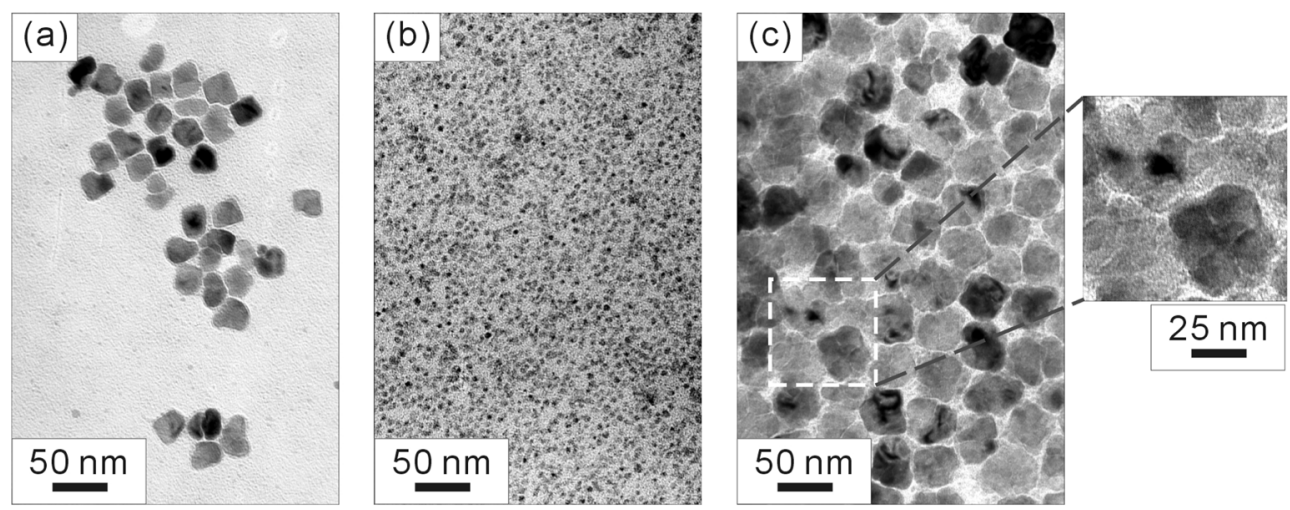

Fig. 1. TEM images of the iron oxide nanoparticles prepared using the same dispersing agents at different conditions: (a) Run R1, with no reductant at $230^{\circ} \mathrm{C}$, (b) Run $\mathrm{R} 2$, with a reductant at $230^{\circ} \mathrm{C}$, and (c) Run $\mathrm{R} 3$, with no reductant at $240^{\circ} \mathrm{C}$. A portion of (c) was enlarged twice as shown separately on the right, revealing each particle to be made up of several smaller particles that are not completely coalesced. 


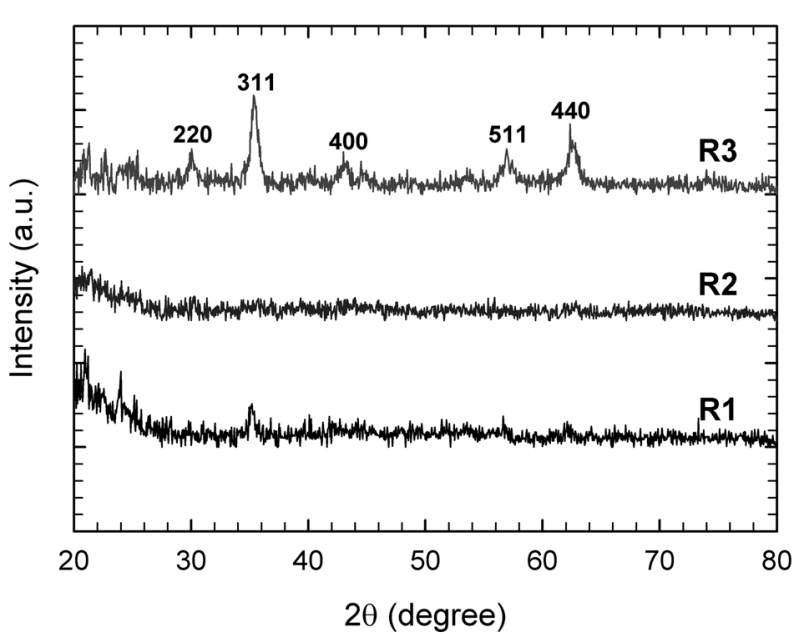

Fig. 2. XRD patterns of the iron oxide nanoparticles prepared with the same dispersing agents at different conditions: (a) Run $\mathrm{R} 1$, with no reductant at $230^{\circ} \mathrm{C}$, (b) Run $\mathrm{R} 2$, with a reductant at $230^{\circ} \mathrm{C}$, and (c) Run $\mathrm{R} 3$, with no reductant at $240^{\circ} \mathrm{C}$. The numbers above the diffraction pattern indicate the XRD peak planes of magnetite.

point, it should be noted that the saturation magnetization (32 emu/g) of the $3 \mathrm{~nm}$ particles synthesized in this study was much higher than that $(<1.25 \mathrm{emu} / \mathrm{g})$ of the $10 \mathrm{~nm}$ magnetite particles prepared by Vijayakumar et al. [12]. However, the coercivity for the larger and smaller particles prepared in this study was 47 Oe and 48 Oe, respectively, which remained relatively constant (Fig. 3). In general, the coercivity decreases with decreasing the particle size when the size belongs to single domain regions [14]. Overall, the iron oxide nanoparticles exhibited a magnetic behavior close to superparamagnetism at room temper-

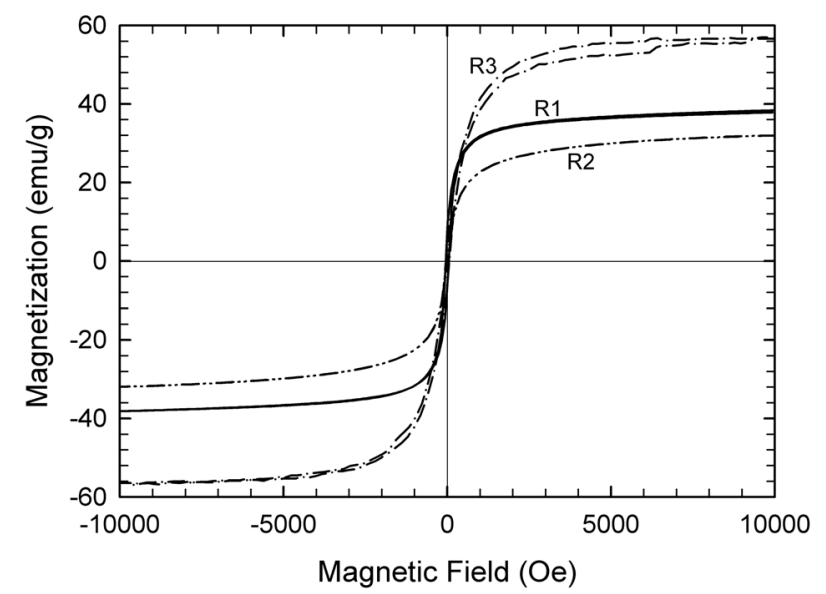

Fig. 3. Room temperature magnetization curves of the iron oxide nanoparticles prepared using the same dispersing agents at different conditions: (a) Run R1, with no reductant at $230^{\circ} \mathrm{C}$, (b) Run $\mathrm{R} 2$, with a reductant at $230^{\circ} \mathrm{C}$, and (c) Run R3, with no reductant at $240^{\circ} \mathrm{C}$. ature (Fig. 3).

Fig. 2 shows the XRD patterns of the nanoparticles. The crystallinity of the nanoparticles were in accordance with the results of selected-area electron diffraction (SAED) measured separately by TEM (data not shown). The precise composition of the iron oxide particles could not be determined by the XRD patterns only because the XRD patterns for magnetite and maghemite are similar. However, it was assumed that the iron oxide nanoparticles synthesized in this study would be composed mainly of magnetite rather than maghemite, even though both phases may coexist [15]. In addition, the color of the nanoparticles was black corresponding to that of magnetite particles, which is in contrast to the brown to brownish red color of maghemite. In addition, maghemite $\left(\gamma-\mathrm{Fe}_{2} \mathrm{O}_{3}\right)$ is usually formed by the oxidation of magnetite $\left(\mathrm{Fe}_{3} \mathrm{O}_{4}\right)$ [16], which is unlikely to occur in the high-purity nitrogen environment used in this study. More precise identification of the composition can be obtained using other techniques, such as Mössbauer spectroscopy.

To further control the particle size, the amounts of dispersing agents were varied with the other conditions fixed. In the case of the dispersing agents, oleylamine 1.0 $\mathrm{ml}$ and TOP $0.3 \mathrm{ml}$ (R4 in Table 1), the iron oxide nanoparticles prepared at $240^{\circ} \mathrm{C}$ were distributed uniformly with a mean size of $6 \mathrm{~nm}(\sigma=11 \%)$. Increasing the amounts of oleylamine and TOP to $1.5 \mathrm{ml}$ and $0.6 \mathrm{ml}$ respectively (R5 in Table 1) caused an increase in the average particle size to $13 \mathrm{~nm}$. In this process, particle synthesis involves generation of supersaturation, nucleation and subsequent growth. The dispersing agents, oleylamine and TOP, can form stable complexes with the individual metal atoms of the precursor prior to nucleation, as suggested by Shevchenko et al. [17]. These complexes may increase the decomposition temperature, which can suppress nucleation, resulting in larger nanoparticles. For a given precursor concentration, smaller number of nuclei gives rise to a larger particle size. Park et al. (2004) also reported an increase in particle size with increasing concentration of dispersing agent in the synthesis of iron oxide nanoparticles [15]. As expected, all the iron oxide nanoparticles synthesized at $240^{\circ} \mathrm{C}$ were not amorphous but crystalline. This temperature might be considered a lower limit for the formation of the crystalline phase in these experiments.

\section{Conclusions}

Nearly monodisperse magnetite nanoparticles were synthesized by thermal decomposition of ferrous acetate, a non-toxic reagent. The particle size was controlled from 5 
to $43 \mathrm{~nm}$ with various mixtures of surfactants, dispersing agents, and reducing agent. However, the size could not be controlled with only a single surfactant or two. Due to the complexity arising from the many constituents, it is difficult to propose a general way of controlling the nanoparticle size in this experimental process. However, it is clear that the particle size can be tuned using combinations of the four dispersing agents and reductant. Furthermore, a uniform size distribution was obtained without the need for a size selection process. The threshold reaction temperature for the synthesis of crystallinestructured nanoparticles was $240^{\circ} \mathrm{C}$. These results suggest that ferrous acetate can replace other harmful ferric or ferrous reagents to fabricate nanostructures for a wide variety of applications.

\section{Acknowledgements}

This study has been performed as a part of the project titled "Technology development for the synthesis of nanomaterials precursors from mineral resources" supported by the Ministry of Knowledge and Economy of Korea.

\section{References}

[1] A. Bee, R. Massart, and S. Neveu, J. Magn. Magn. Mater. 149, 6 (1995).

[2] Y. Sui, D. P. Xu, F. L. Zheng, and W. H. Su, J. Appl. Phys. 80, 719 (1996).

[3] H. F. Yu and A. M. Gadalb, J. Mater. Res. 11, 663 (1996).
[4] N. Moumen, P. Veillet, and M. P. Pileni, J. Magn. Magn. Mater. 149, 67 (1995).

[5] N. S. Kommareddi, M. Tata, V. T. John, G. L. McPherson, M. F. Herman, Y. S. Lee, C. J. O'Connor, J. A. Akkara, and D. L. Kaplan, Chem. Mater. 8, 801 (1996).

[6] K. S. Suslick, M. Fang, and T. Hyeon, J. Am. Chem. Soc. 118, 11960 (1996).

[7] H. C. Shin, J. H. Oh, J. C. Lee, and S. C. Choi, Phys. Status Solidi (A) Appl. Res. 189, 735 (2002).

[8] E. H. Kim, H. S. Lee, and H. Shao, Key. Eng. Mater. 277-279, 1044 (2005).

[9] X. Q. Zhao, F. Zheng, Y. Liang, Z. Q. Hu, Y. B. Xu, and G. B. Zhang, Mater. Lett. 23, 305 (1995).

[10] M. Sivakumar, A. Gedanken, W. Zhong, Y. W. Du, D. Bhattacharya, Y. Yeshurun, and I. Felner, J. Magn. Magn. Mater. 268, 95 (2004).

[11] H. Shao, H. Lee, Y. Huang, I. Ko, and C. Kim, IEEE T Magn. 41, 3388 (2005).

[12] R. Vijayakumar, Y. Koltypin, I. Felner, and A. Gedanken, Mat. Sci. Eng. A-Struct. 286, 101 (2000).

[13] C. B. Murray, S. Sun, H. Doyle, and T. Betley, MRS Bull. 26, 985 (2001).

[14] B. D. Cullity, Introduction to Magnetic Materials Addison-Wesley, London (1972) p. 387.

[15] J. Park, K. An, Y. Hwang, J. E. G. Park, H. J. Noh, J. Y. Kim, J. H. Park, N. M. Hwang, and T. Hyeon, Nat. Mater. 3, 891 (2004).

[16] R. M. Cornell and U. Schwertmann, The Iron Oxides: Structure, Properties, Reactions, Occurences and Uses, 2nd ed. WILEY-VCH, Weinheim (2003) p. 129.

[17] E. V. Shevchenko, D. V. Talapin, H. Schnablegger, A. Kornowski, O. Festin, P. Svedlindh, M. Haase, and H. Weller, J. Am. Chem. Soc. 125, 9090 (2003). 